\title{
Environmental Enrichment Protects Against Cognition Deficits Caused by Sepsis-Associated Encephalopathy
}

Shan Jiang ( $\square$ landjiang@126.com )

China-Japan Friendship Hospital https://orcid.org/0000-0002-7733-4987

\section{Lin Zhao}

900th Hospital of PLA

\section{Yi-Fei Tang}

China-Japan Friendship Hospital

Xi Lu

China-Japan Friendship Hospital

\section{Dan Guo}

China-Japan Friendship Hospital

\section{Research}

Keywords: Sepsis-associated encephalopathy, Environmental enrichment, Standard environment, Cognition deficits

Posted Date: May 6th, 2021

DOI: https://doi.org/10.21203/rs.3.rs-472468/v1

License: (c) (i) This work is licensed under a Creative Commons Attribution 4.0 International License. Read Full License 


\title{
Environmental enrichment protects against cognition deficits caused by Sepsis-associated encephalopathy
}

\author{
Shan Jiang ${ }^{1, a, *}$, Lin Zhao ${ }^{2,3, a}$, Yi-Fei Tang ${ }^{1}$, Xi Lu ${ }^{1}$, Dan Guo ${ }^{1}$ \\ ${ }^{1}$ the China-Japan Friendship Hospital, Beijing 100029, China \\ ${ }^{2}$ the 900th hospital, Fuzhou 350025, China \\ ${ }^{3}$ Fuzong Clinical Medical College of Fujian Medical University, Fuzhou 350025, China

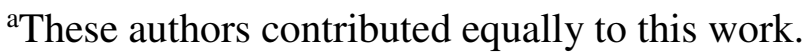 \\ *Corresponding author at: Department of Rehabilitation Medicine, the China-Japan Friendship Hospital; No.2 \\ Ying Hua Yuan East Street, Beijing 100029, PR China. Tel: +86 10 84205480. E-mail: landjiang@ 126.com.
}

\begin{abstract}
:
Background: Sepsis-associated encephalopathy (SAE) is a common complication of sepsis and characterized by impaired cognition ability in survivors. Previous studies revealed that environmental enrichment (EE) ameliorated the cognition deficits in different models of brain injury. However, little research exists exploring the effect of EE on SAE.
\end{abstract}

Methods: our present study was designed to determine the possible benefits of EE in ameliorating the cognition deficits following SAE. To examine the benefits of EE, adult male rats with SAE were placed in an enriched environment or standard environment(SE) for 30 days. After the EE or SE housing, the rats were subjected to a behavioral test battery including sensory neglect test (SN), Elevated Plus Maze test (EPM), Open Field test (OF) Morris water maze test (MWM), and Novel Object Recognition test (NOR).

Results: Our results showed that SAE-induced the impairment of recognition memory (NOR) and spatial learning and memory (MWM) was significantly inhibited in EE exposed rats. In addition, EE exposure also decreased the SAE-induced anxiety-like behavior (EPM) and increased exploratory activity (OF). However, no difference in locomotion ability was detected between the EE and SE exposed rats.

Conclusions: Our results demonstrate the positive effect of $\mathrm{EE}$ on cognitive impairments after SAE. These results highlight the importance of environmental enrichment to prevent cognitive deficits induced by SAE. 


\section{Keywords:}

Sepsis-associated encephalopathy; Environmental enrichment; Standard environment; Cognition deficits

\section{Introduction}

Sepsis is a disease induced by systemic responses to infection with a high and growing prevalence worldwide [1-3]. Sepsis-associated encephalopathy (SAE) is a common complication of sepsis [4]. More than half of patients with severe sepsis shows symptom of SAE, which may be the first manifestation of sepsis before admission to hospital [5]. Dysfunction of consciousness was the acute symptom of SAE, with signs of delirium such as hallucination, somnolence and coma, leading to increased mortality [5-8]. Moreover, there is increasing evidence that SAE may pose substantial risks for long-term cognitive impairments, including alterations in mental processing-speed, executive function, memory, attention, and spatial abilities [9-13]. These can be disabling, lead to poor quality of life and increase social burden placed on both family members and caregivers. Therefore, how to improve the cognition deficits after SAE has been a focus of present studies.

Environmental enrichment (EE), a paradigm consisting of housing conditions that include novelty, social interaction and exercise, has been proved to ameliorate functional deficits associated with various brain injury $[14,15]$. For example, EE can effectively reduce the impact of TBI on sensory impairment and memory deficits, possible via cortical excitability and reorganization [16-20]. EE was also shown to prevent the stroke-induced cognition disorder by increased expression of GFAP in ischemic brain [21.22]. Moreover, in the model of ethol binge-drinking or perinatal asphyxia, experimental evidence pointed to the therapeutic and preventive effects of EE on cognition deficits [23-27]. However, no research exists exploring the effect of $\mathrm{EE}$ on SAE. In recent years, research found that $\mathrm{EE}$ might attenuate the neurobehavioral alterations through inhibition of NADPH Oxidase-2 (Nox2) in the model of juvenile hypoxia [28]. Interestingly, studies also found that SAE-induced cognitive impairments may be mediated by the activation of Nox2 [29,30], indicating that EE is likely to be capable of ameliorating the SAE-induced cognitive deficits. 
Accordingly, the present experiment sought to tests the efficacy of EE in limiting the negative consequence of SAE on cognitive functions. To this end, adult male rats with SAE were placed in an enriched environment. Our data suggest that EE exposure may effectively reduce the impact of SAE on cognition deficits. Thus, directed use of EE may be a viable training mechanism to improve resiliency against the consequences of SAE.

\section{Materials and methods}

\section{Animals}

Sixty-four male Sprague-Dawley (SD) rats (200-250g) were provided by the Animal Center of the China-Japan Friendship Hospital. The experimental procedures were carried out in accordance with the Guidelines for the use of animals in neuroscience research (published in the Membership Directory of the Society, pp 27-28, 1992), and were approved by the committee of Animal Use for Research and Education in China-Japan Friendship Hospital. The animals were housed under a 12-h light/dark cycle in a temperature-controlled room at $24 \pm 1^{\circ} \mathrm{C}$ with free access to food and water.

\section{SAE induction-cecal ligation and perforation (CLP) model}

Rats were subjected to CLP as previously described [31]. Briefly, animals were anesthetized using sodium pentobarbital $(50 \mathrm{mg} / \mathrm{kg})$, given intraperitoneally. Under aseptic conditions, a 3 $\mathrm{cm}$ midline laparotomy was performed to expose the cecum and adjoining intestine. The cecum was ligated with a 3.0 silk suture at its base, below the ileocecal valve, and was perforated once with a 14-gauge needle. The cecum was then squeezed gently to extrude a small amount of feces through the perforation site. The cecum was then returned to the peritoneal cavity, and the laparotomy was closed with 4.0 silk sutures. Animals were resuscitated with regular saline $(50 \mathrm{~mL} / \mathrm{kg}$ ) subcutaneously (s.c.) immediately after and $12 \mathrm{~h}$ after CLP. All animals received antibiotics (ceftriaxone at $30 \mathrm{mg} / \mathrm{kg}$ and clindamycin $25 \mathrm{mg} / \mathrm{kg}$ ) every $6 \mathrm{~h}$ s.c. for a maximum of 3 days. In sham operated group, rats were subjected to all surgical procedures, but the cecum was neither ligated nor perforated. To minimize variability between different experiments, the CLP procedure was always performed by the same investigator. We extensively characterized long-term cognitive impairment using this animal model.

\section{Housing Conditions}


Two housing conditions were used in this study: enriched enviromenent condition (EE) and standard enviromenent condition (SE).

Standard environment (SE): Rats were housed in standard-sized polycarbonate cages $(25 \mathrm{~cm} \times 40 \mathrm{~cm} \times 20 \mathrm{~cm})$, with two rats per cage located in a quiet room. The cages allowed for moderate activity and exploration.

Enriched environment (EE): Rats in the EE group were housed in a large cage $(40 \mathrm{~cm} \times 54 \mathrm{~cm}$ $\times 30 \mathrm{~cm}$ ) with six rats per cage. As previous describe, the cages contained multiple objects including wooden blocks, plastic bone-shaped toys, running wheel and plastic tunnel [32.33]. Suspended ropes allowed for climbing from one level to another. Objects were replaced twice a week. During the enrichment period, food and water were available ad libitum. After 30 days EE housing, the animals were no longer received additional enrichment by removing the levels and toys from the cages.

Rats were assigned in equal numbers to three groups $(n=16)$ : sham group (Sham) (Rats received sham injury and were maintained under standard housing conditions); SAE+SE group (SAE-SE); SAE+EE group (SAE-EE).

\section{Behavioral Testing}

Figure1 provides a schematic representation of the experimental design and timelines. All animals were submitted to behavioral assessment. Animals were naive to all behavioral test procedures and were only manipulated during routine cage cleaning. Behavioral procedures were carried out between 8:00a.m. and 5:00p.m. Testing order of the groups was counterbalanced to avoid the confounding effect of time of the day at which animals were tested.

\section{Sensory Neglect}

The sensory neglect test is used to observe responsivity to focal somatosensory stimuli [34]. All animals were tested for sensory neglect at baseline, before housing (EE or SE) and post-housing (EE or SE). Baseline measurements of sensory neglect were taken one day prior to CLP or sham surgery. Further testing was conducted before housing (EE or SE) and at 1day post-housing (EE or SE). The test consisted of a $2 \mathrm{~cm}$ diameter sticker being placed on the distal-radial area of both forelimbs. The animal was then placed in a clear empty shoebox cage 
and the latency to remove both stickers was recorded. Each animal received 3 trials with approximately 5mins intervals. The maximum length of a trial was 2 mins, at which time any remaining stickers were removed.

\section{Elevated Plus Maze}

Anxiety-like behaviors were assessed in the elevated-plus maze (EPM), which was composed of two opposing open arms $(10.2 \times 10.2 \mathrm{~cm})$ and two opposing closed arms $(10.2 \times 10.2 \mathrm{~cm}$; with $30.5 \mathrm{~cm}$-high walls) with a common central square all made of black Plexiglas [35]. The EPM was elevated $100 \mathrm{~cm}$ above the floor and indirectly illuminated (light intensity in open arms:85-90Lux). Rats were individually placed at the extremity of a closed arm of the maze (facing away from the center) and each rat was tested for one $5 \mathrm{~min}$ trial with $70 \%$ ethanol cleaning and totally dried with paper towels after each trial. Ethovision software was used to record the latency to enter an open arm as well as time spent in and number of entries to (defined by all four paws being in an arm) open and closed arms. Behaviors were recorded including rearing and head dipping.

\section{Open Field Test}

In this study, open field (OF) test was assessed in an open field apparatus to evaluate both locomotor and exploratory activities [29]. The apparatus is a $60 \mathrm{~cm} \times 60 \mathrm{~cm}$ open field surrounded by $60 \mathrm{~cm}$ high walls made of brown plywood with a frontal glass wall. The floor of the open field is divided into nine rectangles by black lines. The animals were gently placed on the central area when its four paws were on it. The arena was uniformly and indirectly illuminated (light intensity in the center of the OF: 70 lux). Rats were allowed 5 min of free exploration of the apparatus. Dependent variables were: distance traveled in the OF, number of rears (standing upright with or without touching the walls with the forepaws), line crossings (horizontal activity), time spent in the center square $(30 \times 30 \mathrm{~cm})$ and time spent in the 4 corner squares $(10 \times 10 \mathrm{~cm})$ of the maze. Between sessions, the apparatus was cleaned with $70 \%$ ethanol.

\section{Morris water maze}

The Morris water maze (MWM) is an established test of spatial learning and reference/working memory [36,37]. Animals were placed in a $178 \mathrm{~cm}$ diameter dark circular 
tank filled with water (approximately $37 \mathrm{~cm}$ deep). The tank was divided evenly into four quadrants (A, B, C, D) with appropriate marking of the quadrants on the top edge of the tank. A $10.2 \mathrm{~cm}$ diameter clear plexiglass platform was submerged to a depth of $2 \mathrm{~cm}$ below waterline and placed approximately $28 \mathrm{~cm}$ from the wall of the pool in quadrant C. Latency to find the hidden platform was recorded using Ethovision software that tracked and timed the animals in the tank until they reached the platform. Spatial learning consisted of providing a block of four daily trials (4-min inter-trial interval) for five consecutive days to locate the submerged platform (i.e., invisible to the rat). For each daily block of trials, the rats were placed in the pool facing the wall at each of the four possible start locations in a randomized manner. Each trial lasted until the rat climbed onto the platform or until $120 \mathrm{~s}$ had elapsed, whichever occurred first. Rats that failed to locate the platform within the allotted time were manually guided to it. The rats remained on the platform for $30 \mathrm{~s}$ before placed in a heated incubator between trials. On day 6 , the platform was raised $2 \mathrm{~cm}$ above the water surface (i.e., visible to the rat) as a control procedure to determine the contributions of non-spatial factors on cognitive performance. The times of the 4 daily trials for each rat were averaged and used in the statistical analyses. Also on day 6, but before the visible platform assessment, all rats were given a single probe trial to measure memory retention. Briefly, the platform was removed, and the rats were given the opportunity to explore the pool for $30 \mathrm{~s}$. The percent time spent in the target quadrant was used in the statistical analysis.

\section{Novel Object Recognition Task}

The Novel Object Recognition Task (NORT) is a behavioral test that was developed to assess non-spatial working memory $[38,39]$. In the present study, this specific type of memory will be called "recognition memory". NORT procedures were based on established protocols [40]. The NORT took place in the same apparatus as OF and comprised two phases. During the first phase of the familiarization period, rats were presented with two identical objects (placed in opposite corners of the arena) and their exploration was recorded over $5 \mathrm{~min}$. Rats were returned to their cages during the phase interval. One hour later, one of the two familiar objects were replaced with a novel object and the rats were again allowed to explore them for $3 \mathrm{~min}$ (test phase). To eliminate a certain variation by emotional instability, rats with excessive freezing behavior more than $60 \%$ out of the whole period of test phase were excluded from analysis. Time spent 
exploring each object was defined as directing the nose at the object at a distance of $<1 \mathrm{~cm}$ and exploring it (i.e. sniffing or otherwise interacting with the object). Object exploration was not scored if the animal was in contact with but not facing the object, or if it sat on the object or used it as a prop (Ennaceur \& Delacour, 1988). Discrimination index (d1) and discrimination ratio $(\mathrm{d} 2)$ scores were calculated using the following formulas: $\mathrm{d} 1=\mathrm{tn}-\mathrm{tf}$, and $\mathrm{d} 2=(\mathrm{tn}-\mathrm{tf}) /(\mathrm{tn}+$ $\mathrm{tf})$, where $\mathrm{tn}=$ the amount of time rats explored the novel object and $\mathrm{tf}=$ the amount of time rats explored the familiar object

\section{Statistical analysis}

The results were expressed as the mean \pm S.E.M. A One-Way analysis of variance was used to compare groups SAE-EE, SAE-SE, and Sham. If day was included as a factor, a mixed-design ANOVA was used. The null hypothesis was rejected when the two tailed probability value was $5 \%$ or less $(\mathrm{p} \leqslant 0.05)$. Data were analyzed with Statistical Product and Service Solutions (Version 18.0). Since the specific hypotheses tests were identified a priori, planned comparisons were performed regardless of the outcome of the ANOVA. Post-hoc paired comparisons of groups used Tukey simultaneous confidence intervals with a 0.05 experimentwise error level.

\section{Results}

Five rats were excluded from all analyses (3 SAE-SE, and 2 SAE-EE) due to death or poor post-surgical recovery, resulting in the following sample sizes for behavioral analysis: 16 Sham, 13 SAE-SE, 14 SAE-EE.

\section{Sensory neglect in the SN test}

In this part, the effect of EE on somatosensory was determined. Prior to CLP, there was no significant difference of baseline on latency to sticker removal between three groups $(\mathrm{F}(2,40)=$ 0.0463, $\mathrm{p}>0.05$ ). Following CLP (prior to housing), there were significant differences on sticker removal latency $(\mathrm{F}(2,40)=238.5, \mathrm{p}<0.001)$. Post-hoc analysis indicated that both SAE-SE and SAE-EE groups removed the stickers significantly slower than the sham group (vs Sham group: $\mathrm{p}<0.001$, Figure.2), indicating that SAE impaired the somatosensory. However, after 30 days housing (EE or SE), SAE-EE group removed the stickers faster than the SAE-SE group (vs SAE-SE group: $\mathrm{p}<0.05$, Figure.2) and had no difference with sham group (vs Sham 
group: $\mathrm{p}>0.05$, Fig.2). Taken together, our results revealed that SAE-induced sensory neglect deficits were attenuated when enrichment was applied.

\section{Anxiety-related behaviors in the EPM test}

After 30 days housing (EE or SE), the anxiety-related behaviors were tested by EPM. Figure 3 depicts behaviors in the elevated-plus maze among SE and EE rats. Latency to enter an open arm as well as time spent in the open/closed arms, entries in the open/closed arms, head dipping, rearing, and grooming were tested as indicators of anxiety-related behaviors in the EPM. ANOVA tests revealed that the rats in three groups did not differ in their time spent in head dipping, rearing, and grooming $(\mathrm{F}(2,40)=0.1618, \mathrm{p}>0.05 ; \mathrm{F}(2,40)=1.511, \mathrm{p}>0.05 ; \mathrm{F}(2$, $40)=0.515, \mathrm{p}>0.05$, respectively; Fig.3A,B,C). However, there were significant effects of groups on open arm time $(\mathrm{F}(2,40)=9.085, \mathrm{p}<0.01 ; \mathrm{Fig} .3 \mathrm{G})$, latency to enter an open arm $(\mathrm{F}(2$, $40)=15.05, \mathrm{p}<0.01$; Fig.3D) and entries in the closed arms $(\mathrm{F}(2,40)=25.89, \mathrm{p}<0.01$; Fig.3F $)$. Pairwise comparisons confirmed that the SAE rats reared in EE showed a significantly higher open arm time (vs SAE-SE group: $\mathrm{p}<0.01$, Fig.3G) compared to the SAE rats reared in SE and had no difference with sham group (vs Sham group: $p>0.05$, Fig.3G). Correspondingly, the SAE rats housed in EE also had decreased escape latency and took shorted time to enter an open arm (vs SAE-SE: p<0.05; Fig.3D). The rats in SAE-SE groups also exhibited the increased entries in the closed arms than in SAE-EE group and sham group (vs SAE-EE or Sham group: $p$ $<0.001$; Fig.3F). These results indicate that SAE rats reared in EE displayed reduced anxiety-related behaviors.

\section{Locomotion and exploratory activity in the OF test}

As revealed in Fig.4A,B,C no significant differences were observed in the total distance traveled and number of line crossings and rears in the OF test among the three groups $(\mathrm{F}(2,40)$ $=0.05891, \mathrm{p}>0.05 ; \mathrm{F}(2,40)=0.1949, \mathrm{p}>0.05 ; \mathrm{F}(2,40)=0.2132, \mathrm{p}>0.05$, respectively $)$ suggesting sepsis or environment did not affect the general locomotor activity, horizontal locomotor activity (line crossings) and vertical locomotor activity (rearing). Regarding exploratory activity, the results showed that SAE-SE groups spent more time in the corner squares (vs Sham group: $\mathrm{p}<0.001$; Fig.4D) and less time in the center square (vs Sham group: $\mathrm{p}$ $<0.001$; Fig.4E) than sham group, indicating SAE impaired the exploratory behavior. Additionally, we also found SAE rats housed in EE made more time in the center square (vs 
SAE-SE group: $\mathrm{p}<0.01$; Fig.4E), and less time in the corner squares when compared with SAE rats housed in SE (vs SAE-SE group: $\mathrm{p}<0.05$; Fig.4D). These results mean that SAE rats displayed an exploratory activity impairment that was counteracted by EE.

\section{Spatial learning and reference/working memory in the MWM test}

In this part, the effect of $\mathrm{EE}$ on spatial learning and reference/working memory was determined. We examined the learning and memory ability after infrasound exposure by MWM, a hippocampus-dependent learning and memory task.

In the spatial learning testing, escape latencies were recorded for 5 consecutive days. A mixed-design ANOVA showed there was a significant difference among the groups $(\mathrm{F}(2,40)=$ 24.67, p $<0.001$; Fig.5A). The post-hoc analysis revealed that the sham group reached the submerged platform quicker than the SAE-SE groups at day 4 and day 5, indicative of an impairment of spatial learning after SAE (vs SAE-SE group: $\mathrm{p}<0.001$; Fig.5A). However, from 3 day on, among the two SAE groups, the SAE-EE group also performed better latency to platform than the SAE-SE group (vs SAE-SE group: $\mathrm{p}<0.001$; Fig.5A). At day 6, no significant differences in latency to visible platform were observed among the groups $(\mathrm{F}(2,40)=1.380, \mathrm{p}$ $>0.05$; Fig.5B), confirming that the differences observed in escape latencies could not be attributed to vision. These results suggest that EE ameliorated the SAE-induced spatial learning deficits.

On the last day of MWM testing, the platform was removed and time spent in quadrant $\mathrm{C}$ was analyzed for reference/working memory retention. Analysis of the probe data revealed that enhanced memory retention, as demonstrated by a greater percentage of the $30 \mathrm{~s}$ allotted time spent in quadrant $\mathrm{C}$, was observed in the Sham group and SAE-EE groups relative to the SAE-SE group $(F(2,40)=10.98, p<0.001$; Sham vs SAE-SE group: $p<0.001$; SAE-SE vs SAE-SE group: $\mathrm{p}<0.05$; Fig.5C). Lastly, no significant differences in swim speed were observed among the three groups $(\mathrm{F}(2,40)=0.7141 \mathrm{p}>0.05$; Fig.5D), indicating that no motor deficits attributed to the differences.

\section{Recognition memory in the NORT test}

In order to investigate the effect of EE on non-spatial working memory (recognition memory), NORT test was introduced. One-Way ANOVA tests and subsequent post-hoc analysis performed on discrimination index (d1) and discrimination ratio (d2) scores indicated that 
recognition memory was deteriorated after $\operatorname{SAE}(\mathrm{F}(2,40)=5.494, \mathrm{p}<0.01$; Sham VS SAE-SE group: d1:p $<0.05$; d2: $\mathrm{p}<0.05$; Fig.6A,B). As expected, EE was able to improve recognition memory when compared with SAE-SE group (SAE-EE VS SAE-SE group: d1:p $<0.05$; $d 2$ : $\mathrm{p}<$ 0.05; Fig.6A,B), indicated by the increase of $\mathrm{d} 1$ and $\mathrm{d} 2$. Thus, the results revealed that $\mathrm{EE}$ was effective to attenuate the SAE-induced recognition memory impairment.

\section{Discussion}

As sepsis complications, SAE is thought to occur due to a combination of neuroinflammation and disturbances in cerebral perfusion, the blood brain barrier (BBB) and neurotransmission [41.42]. At present, SAE is the most frequent causes of morbidity and mortality in intensive care units (ICUs) [5]. Survivors with long term cognitive impairments that can be disabling. Due to poor understanding about the pathophysiology of SAE, there is no effective treatment to ameliorate the cognition deficits after SAE.

EE intervention is a new, simple, and effective treatment that is widely used in medical practice, including rehabilitation for cognitive impairment. The results of the present study provide evidence that $\mathrm{EE}$ after $\mathrm{SAE}$ results in sparing of cognition function. 1 month of enrichment after SAE in adult animals blocked the deleterious effects of SAE on sensory discrimination, exploratory activity, spatial learning and reference/working memory and relieved anxiety-related behaviors, indicated by performances in the SN, MWM, EPM and OF. Enriched rats therefore had a better prognosis following SAE. This is likely caused by effects of $\mathrm{EE}$ on neuroplastic responses to injury. The finding that an $\mathrm{EE}$ can reduce the cognition impairment of SAE is in accord with similar observations in animals with other forms of brain dysfunction [43-48]. Healthy environments also afford similar benefits to humans. It is well known, for example, that environmental and lifestyle factors can influence the process of normal cognitive aging [49], reduce cognitive impairment caused by traumatic brain injury [46], and delay the onset of dementia associated with progressive neurological disease [50].

The sensory neglect task is a good indicator of responsiveness to focal somatosensory stimuli and reveals significant impairments resulting from injury to prefrontal cortex [34]. In present study, we found that SAE rats given EE showed better improvement in responding to focal somatosensory stimuli compared to SAE given SE in the SN task, suggesting the positive effects 
of EE on prefrontal cortex. It has been previously reported that deficiency of brain-derived neurotrophic factor (BDNF) levels was associated with the significantly impaired somatosensory behavior [51]. Interestingly, recent studies found that expression of BDNF was induced by EE [52,53], which maybe the mechanism underlying EE ameliorating somatosensory.

The EPM is used frequently to test for anxiety-like behavior and time in the open arm of the maze is taken to indicate reduced anxiety, an interpretation supported by increased open arm time following administration of anxiolytics such as diazepam [54]. Our results showed that rats subjected to EE exhibited decreased anxiety-related behaviors compared to SAE-SE rats. This result is in agreement with previous research where the anxiolytic effect of EE has been well documented [55-58], with slight differences due to model used. In EE-reared animals, it has been reported a reduction in anxiety-related behaviors, together with decreased hypothalamic-pituitary-adrenal (HPA) axis responses [59] and altered gene expression in the amygdala and the hypothalamus [60]. This suggests us all key brain regions involved in this response. It is important to note that prefrontal damage can increase risk-taking behavior [61] which may result in increased open arm time via a non-anxiety related mechanism [62]. Therefore, in this test, we cannot rule out the contribution of risk-taking behavior in the increased time spent in the open arms.

Consistented with previous studies, in the OF and MWM test, general locomotion activity and habituation were unaffected in SAE rats. However, in the OF test, exploratory activity in SAE-SE rats was impairment by spending more time in the corners of the OF. Additionally, we also found the impairment in exploratory activity in SAE rats was partially overcome by EE. It was shown, in LPS-treated rats, the reduced cholinergic innervation in barrel cortex might cause such behavioral changes as the integrity of cholinergic innervation in cortical barrel fields is necessary for plastic processes [63]. Recently, we observed EE induced the increased cholinergic innervation in barrel cortex after (unpublished data). Accordingly, it is proposed that EE may increase exploratory activity by changing the cholinergic innervation in barrel cortex.

Findings from the MWM indicated that EE blocks the development of spatial learning and memory deficits due to SAE. Because the animal relies solely on spatial cues and memory, 
decreased latency to the platform is indicative of improved spatial learning and memory. The fact that MWM swim speeds were similar among the groups indicates that there were no motor deficits associated with performance in MWM, and thus impaired MWM performance in the SAE group can be interpreted to represent spatial learning and memory deficits. It has also been shown that MWM learning impairments are independent of locomotor effects because land-based locomotor reductions did not affect swimming speed. In this study, SAE-EE rats performed better than SAE-SE rats, indicating that EE blocks the deleterious effects of SAE. MWM performance was linked to long-term potentiation (LTP) and NMDA receptor function [64], making it a key technique in the investigation of hippocampal circuitry. A growing number of studies found that EE's positive role in the improvement of LTP and neuronal regeneration in the hippocampus [65,66], which may construct the basis for the improvement of MWM performance after EE.

NORT test is a simple behavioral assay of recognition memory that rely primarily on a rodent's innate exploratory behavior in the absence of externally applied rules or reinforcement. In our study, an expected finding was that EE ameliorated the SAE-induced impairment of recognition memory. The results also reflected the improvement of attention, anxiety, and preference for novelty in SAE rats after EE. The increased preference to novel objects showed a conditioned association between environmental cues and the appetitive effects of receiving access to novel stimuli [67] and means that presentation of the familiar object exists in animals' memory [68]. It is widely accepted that in both the monkey and the rat brain, the perirhinal cortex plays an important role in object recognition memory [69], i.e., the ability to evaluate a previously encountered item as familiar depending on the integrity of the medial temporal lobe [70]. This brain structure plays an important role in recognition memory formation,. Hence, the positive effect of EE may be achieved by acting on this brain structure.

The primary goal of this study was to evaluate the impact of EE on the cognition deficits caused by SAE. The enriched cohort was therefore exposed to a SAE. An ideal design would also include a Sham-EE group. This group would have facilitated the comparison of identical housing conditions, thus elucidating the benefit of EE for injured animals. Nevertheless, the behavioral results from the current experimental design indicate a neuroprotective benefit of EE. These finding are also in line with the large quantities of therapeutic research concluding EE is 
beneficial after injury. However, currently, the mechanisms governing EE-mediated behavioral improvements after injury are unclear. There are many mechanisms involving in the EE-induced neural function improvement. Early studies in rodents indicate that EE increases total brain and cortical weight [71]. Subsequent studies document additional benefits of EE including increased neuronal density [72], dendritic branching [73] and neuronal transmission [74], and enhanced neurotrophic growth factor expression [75]. EE-induced hormonal and neurostructural changes are also associated with improvements of neural function [76.77].

In summary, the results of this study indicate that EE is protective against the functional deficits of SAE. The EE concept may therefore be a viable training mechanism to improve resiliency against the consequences of SAE. Future studies are necessary to further explore the possible neuroplastic mechanisms responsible for the protection.

\section{Conclusions}

The results of the present study demonstrate that EE is effective against the cognitive deficits after SAE and emphasize the critical role of oxidative damage and may be a viable training mechanism to improve resiliency against the cognitive dysfunction after sepsis.

\section{Abbreviations}

SAE: Sepsis-associated encephalopathy; EE: environmental enrichment; SE: standard environment; SN: sensory neglect test; EPM: Elevated Plus Maze test; OF: Open Field test; MWM: Morris water maze test; NOR: Novel Object Recognition test.

\section{Declarations}

\section{Acknowledgements}

We thank the staffs at the Clinical Research Institute of China-Japan Friendship Hospital and Trauma Research Center of Fourth Medical Center of the Chinese PLA General Hospital for providing experimental space, facilities, and technical services.

\section{Authors' contributions}

SJ MD and LZ MD designed study and drafted the manuscript. YFT MD, XL MD and DG MD performed the behavioral tests. SJ MD and YFT MD performed the statistical analysis. DG MD helped to draft the manuscript. All authors read and approved the final manuscript. 


\section{Funding}

This study was supported by the Natural Science Foundation of Beijing Municipality (CN) (Grant No.7212102).

\section{Availability of data and materials}

The datasets used and/or analyzed during the current study are available from the corresponding author on reasonable request.

\section{Ethics approval and consent to participate}

All surgical procedures and experimental protocols were approved by the committee of Animal Use for Research and Education in China-Japan Friendship Hospital in Beijing.

\section{Consent for publication}

Not applicable.

\section{Competing interests}

The authors declare that they have no competing interests.

\section{Author details}

${ }^{1}$ Department of rehabilitation medicine, the China-Japan Friendship Hospital, No.2 Ying Hua Yuan East Street, Beijing 100029, China. ${ }^{2}$ Department of Neurosurgery, the 900th hospital, Fuzhou 350025, China. ${ }^{3}$ Fuzong Clinical Medical College of Fujian Medical University, Fuzhou 350025, China.

\section{References}

1. Rello J, Valenzuela-Sánchez F, Ruiz-Rodriguez M, Moyano S. Sepsis: A Review of Advances in Management. Adv Ther. 2017; 34:2393-2411.

2. Angus DC, Linde-Zwirble WT, Lidicker J, Clermont G, Carcillo J, Pinsky MR. Epidemiology of severe sepsis in the United States: analysis of incidence, outcome, and associated costs of care. Crit Care Med. 2001; 29:1303-1310.

3. McBride MA, Patil TK, Bohannon JK, Hernandez A, Sherwood ER, Patil NK. Immune Checkpoints: Novel Therapeutic Targets to Attenuate Sepsis-Induced Immunosuppression. Front Immunol. 2021; 11:624272.

4. Li Y, Yin L, Fan Z, Su B, Chen Y, Ma Y, Zhong Y, Hou W, Fang Z, Zhang X. Microglia: A Potential Therapeutic Target for Sepsis-Associated Encephalopathy and Sepsis-Associated Chronic Pain. Front Pharmacol. 2020; 11:600421.

5. Gofton TE, Young GB. Sepsis-associated encephalopathy. Nat Rev Neurol. 2012; 8:557-566.

6. Lamar CD, Hurley RA, Taber KH. Sepsis-associated encephalopathy: review of the neuropsychiatric 
manifestations and cognitive outcome. J Neuropsychiatry Clin Neurosci. 2011; 23:237-241.

7. Heming N, Mazeraud A, Verdonk F, Bozza FA, Chrétien F, Sharshar T. Neuroanatomy of sepsis-associated encephalopathy. Crit Care. 2017; 21:65.

8. Chung HY, Wickel J, Brunkhorst FM, Geis C. Sepsis-Associated Encephalopathy: From Delirium to Dementia? J Clin Med. 2020; 9:703.

9. Iwashyna TJ, Ely EW, Smith DM, Langa KM. Long-term cognitive impairment and functional disability among survivors of severe sepsis. JAMA. 2010; 304:1787-1794.

10. Semmler A, Widmann CN, Okulla T, Urbach H, Kaiser M, Widman G, Mormann F, Weide J, Fliessbach K, Hoeft A, Jessen F, Putensen C, Heneka MT. Persistent cognitive impairment, hippocampal atrophy and EEG changes in sepsis survivors. J Neurol Neurosurg Psychiatry. 2013;84: 62-69.

11. Prescott HC. Variation in Postsepsis Readmission Patterns: A Cohort Study of Veterans Affairs Beneficiaries. Ann Am Thorac Soc. 2017; 14:230-237.

12. Iwashyna TJ, Speelmon EC. Advancing a Third Revolution in Critical Care. Am J Respir Crit Care Med. 2016; 194:782-783.

13. Kaukonen KM, Bailey M, Suzuki S, Pilcher D, Bellomo R. Mortality related to severe sepsis and septic shock among critically ill patients in Australia and New Zealand, 2000-2012. JAMA. 2014; 311:1308-1316.

14. van Praag H, Kempermann G, Gage FH. Neural consequences of environmental enrichment. Nat Rev Neurosci. 2000; 1:191-198.

15. Rojas-Carvajal M, Sequeira-Cordero A, Brenes JC. The environmental enrichment model revisited: a translatable paradigm to study the stress of our modern lifestyle. Eur J Neurosci. 2021. doi: 10.1111/ejn.15160. Epub ahead of print.

16. Alwis DS, Yan EB, Johnstone V, Carron S, Hellewell S, Morganti-Kossmann MC, Rajan R. Environmental Enrichment Attenuates Traumatic Brain Injury: Induced Neuronal Hyperexcitability in Supragranular Layers of Sensory Cortex. J Neurotrauma. 2016; 33:1084-1101.

17. Redell JB, Maynard ME, Underwood EL, Vita SM, Dash PK, Kobori N. Traumatic brain injury and hippocampal neurogenesis: Functional implications. Exp Neurol. 2020; 331:113372.

18. Tang BL. Axon regeneration induced by environmental enrichment- epigenetic mechanisms. Neural Regen Res. 2020; 15: 10-15.

19. Gaulke LJ, Horner PJ, Fink AJ, McNamara CL, Hicks RR. Environmental enrichment increases progenitor cell survival in the dentate gyrus following lateral fluid percussion injury. Brain Res Mol Brain Res. 2005; 141:138-150.

20. Horner PJ, Gage FH. Regenerating the damaged central nervous system. Nature. 2000; 407: 963-970.

21. Gonçalves LV, Herlinger AL, Ferreira TAA, Coitinho JB, Pires RGW, Martins-Silva C. Environmental enrichment cognitive neuroprotection in an experimental model of cerebral ischemia: biochemical and molecular aspects. Behav Brain Res. 2018; 348:171-183.

22. Zhang X, Yuan M, Yang S, Chen X, Wu J, Wen M, Yan K, Bi X. Enriched environment improves post-stroke cognitive impairment and inhibits neuroinflammation and oxidative stress by activating Nrf2-ARE pathway. Int J Neurosci. 2020:1-9. doi: 10.1080/00207454.2020.1797722. Epub ahead of print.

23. Rodríguez-Ortega E, de la Fuente L, de Amo E, Cubero I. Environmental Enrichment During Adolescence 
Acts as a Protective and Therapeutic Tool for Ethanol Binge-Drinking, Anxiety-Like, Novelty Seeking and Compulsive-Like Behaviors in C57BL/6J Mice During Adulthood. Front Behav Neurosci. 2018; 12:177.

24. Rico-Barrio I, Peñasco S, Puente N, Ramos A, Fontaine CJ, Reguero L, Giordano ME, Buceta I, Terradillos I, Lekunberri L, Mendizabal-Zubiaga J, Rodríguez de Fonseca F, Gerrikagoitia I, Elezgarai I, Grandes P. Cognitive and neurobehavioral benefits of an enriched environment on young adult mice after chronic ethanol consumption during adolescence. Addict Biol. 2019; 24:969-980.

25. Diaz R, Miguel PM, Deniz BF, Confortim HD, Barbosa S, Mendonça MCP, da Cruz-Höfling MA, Pereira LO. Environmental enrichment attenuates the blood brain barrier dysfunction induced by the neonatal hypoxia-ischemia. Int J Dev Neurosci. 2016; 53:35-45.

26. Schuch CP, Diaz R, Deckmann I, Rojas JJ, Deniz BF, Pereira LO. Early environmental enrichment affects neurobehavioral development and prevents brain damage in rats submitted to neonatal hypoxia-ischemia. Neurosci Lett. 2016; 617:101-107.

27. Galeano P, Blanco E, Logica Tornatore TM, Romero JI, Holubiec MI, Rodríguez de Fonseca F, Capani F. Life-long environmental enrichment counteracts spatial learning, reference and working memory deficits in middle-aged rats subjected to perinatal asphyxia. Front Behav Neurosci. 2015; 8:406.

28. Zhang M, Wu J, Huo L, Luo L, Song X, Fan F, Lu Y, Liang D. Environmental Enrichment Prevent the Juvenile Hypoxia-Induced Developmental Loss of Parvalbumin-Immunoreactive Cells in the Prefrontal Cortex and Neurobehavioral Alterations Through Inhibition of NADPH Oxidase-2-Derived Oxidative Stress. Mol Neurobiol. 2016; 53:7341-7350.

29. Ji MH, Qiu LL, Tang H, Ju LS, Sun XR, Zhang H, Jia M, Zuo ZY, Shen JC, Yang JJ. Sepsis-induced selective parvalbumin interneuron phenotype loss and cognitive impairments may be mediated by NADPH oxidase 2 activation in mice. J Neuroinflammation. 2015; 12:182.

30. Hernandes MS, D'Avila JC, Trevelin SC, Reis PA, Kinjo ER, Lopes LR, Castro-Faria-Neto HC, Cunha FQ, Britto LR, Bozza FA. The role of Nox2-derived ROS in the development of cognitive impairment after sepsis. J Neuroinflammation. 2014; 11:36.

31. Sun $\mathrm{X}$, Zhou R, Lei $\mathrm{Y}$, Hu J, Li X. The ligand-gated ion channel P2X7 receptor mediates NLRP3/caspase-1-mediated pyroptosis in cerebral cortical neurons of juvenile rats with sepsis. Brain Res. 2020; 1748:147109.

32. Briones TL, Klintsova AY, Greenough WT. Stability of synaptic plasticity in the adult rat visual cortex induced by complex environment exposure. Brain Res. 2004; 1018:130-135.

33. Lippert-Gruener M, Maegele M, Garbe J, Angelov DN. Late effects of enriched environment (EE) plus multimodal early onset stimulation (MEOS) after traumatic brain injury in rats: Ongoing improvement of neuromotor function despite sustained volume of the CNS lesion. Exp Neurol. 2007; 203:82-94.

34. Hoffman SW, Virmani S, Simkins RM, Stein DG. The delayed administration of dehydroepiandrosterone sulfate improves recovery of function after traumatic brain injury in rats. J Neurotrauma. 2003; 20:859-870.

35. Benaroya-Milshtein N, Hollander N, Apter A, Kukulansky T, Raz N, Wilf A, Yaniv I, Pick CG. Environmental enrichment in mice decreases anxiety, attenuates stress responses and enhances natural killer cell activity. Eur J Neurosci. 2004; 20:1341-1347.

36. Morris R. Developments of a water-maze procedure for studying spatial learning in the rat. J Neurosci 
Methods. 1984; 11:47-60.

37. Tucker LB, Fu AH, McCabe JT. Hippocampal-Dependent Cognitive Dysfunction Following Repeated Diffuse Rotational Brain Injury in Male and Female Mice. J Neurotrauma. 2021. doi: 10.1089/neu.2021.0025. Epub ahead of print.

38. Braun MD, Kisko TM, Witt SH, Rietschel M, Schwarting RKW, Wöhr M. Long-term environmental impact on object recognition, spatial memory and reversal learning capabilities in Cacnalc-haploinsufficient rats. Hum Mol Genet. 2019; 28:4113-4131.

39. Marshall HJ, Pezze MA, Fone KCF, Cassaday HJ. Age-related differences in appetitive trace conditioning and novel object recognition procedures. Neurobiol Learn Mem. 2019; 164:107041..

40. Pezze MA, Marshall HJ, Fone KC, Cassaday HJ. Dopamine D1 receptor stimulation modulates the formation and retrieval of novel object recognition memory: Role of the prelimbic cortex. Eur Neuropsychopharmacol. 2015; 25:2145-2156.

41. Adam N, Kandelman S, Mantz J, Chrétien F, Sharshar T. Sepsis-induced brain dysfunction. Expert Rev Anti Infect Ther. 2013; 11:211-221.

42. Comim CM, Cassol OJ Jr, Constantino LS, Felisberto F, Petronilho F, Rezin GT, Scaini G, Daufenbach JF, Streck EL, Quevedo J, Dal-Pizzol F. Alterations in inflammatory mediators, oxidative stress parameters and energetic metabolism in the brain of sepsis survivor rats. Neurochem Res. 201; 36:304-311.

43. Dhanushkodi A, Shetty AK. Is exposure to enriched environment beneficial for functional post-lesional recovery in temporal lobe epilepsy? Neurosci Biobehav Rev. 2008; 32:657-674.

44. Janssen H, Bernhardt J, Collier JM, Sena ES, McElduff P, Attia J, Pollack M, Howells DW, Nilsson M, Calford MB, Spratt NJ. An enriched environment improves sensorimotor function post-ischemic stroke. Neurorehabil Neural Repair. 2010; 24:802-813.

45. Hannan AJ. Environmental enrichment and brain repair: harnessing the therapeutic effects of cognitive stimulation and physical activity to enhance experience-dependent plasticity. Neuropathol Appl Neurobiol. 2014; 40:13-25.

46. Bondi CO, Semple BD, Noble-Haeusslein LJ, Osier ND, Carlson SW, Dixon CE, Giza CC, Kline AE. Found in translation: Understanding the biology and behavior of experimental traumatic brain injury. Neurosci Biobehav Rev. 2015; 58:123-146.

47. Zhuang ZQ, Zhang ZZ, Zhang YM, Ge HH, Sun SY, Zhang P, Chen GH. A Long-Term Enriched Environment Ameliorates the Accelerated Age-Related Memory Impairment Induced by Gestational Administration of Lipopolysaccharide: Role of Plastic Mitochondrial Quality Control. Front Cell Neurosci. 2021; 14:559182.

48. Guan SZ, Fu YJ, Zhao F, Liu HY, Chen XH, Qi FQ, Liu ZH, Ng TB. The mechanism of enriched environment repairing the learning and memory impairment in offspring of prenatal stress by regulating the expression of activity-regulated cytoskeletal-associated and insulin-like growth factor-2 in hippocampus. Environ Health Prev Med. 2021; 26:8.

49. Kramer AF, Bherer L, Colcombe SJ, Dong W, Greenough WT. Environmental influences on cognitive and brain plasticity during aging. J Gerontol A Biol Sci Med Sci. 2004; 59:M940-957.

50. Bialystok E, Craik FI, Freedman M. Bilingualism as a protection against the onset of symptoms of 
dementia. Neuropsychologia. 2007; 45:459-464.

51. García-Piqueras J, García-Mesa Y, Cárcaba L, Feito J, Torres-Parejo I, Martín-Biedma B, Cobo J, García-Suárez O, Vega JA. Ageing of the somatosensory system at the periphery: age-related changes in cutaneous mechanoreceptors. J Anat. 2019; 234:839-852.

52. Cordier JM, Aguggia JP, Danelon V, Mir FR, Rivarola MA, Mascó D. Postweaning Enriched Environment Enhances Cognitive Function and Brain-Derived Neurotrophic Factor Signaling in the Hippocampus in Maternally Separated Rats. Neuroscience. 2021; 453:138-147.

53. Yu KW, Wang CJ, Wu Y, Wang YY, Wang NH, Kuang SY, Liu G, Xie HY, Jiang CY, Wu JF. An enriched environment increases the expression of fibronectin type III domain-containing protein 5 and brain-derived neurotrophic factor in the cerebral cortex of the ischemic mouse brain. Neural Regen Res. 2020; 15:1671-1677.

54. Pellow S, Chopin P, File SE, Briley M. Validation of open:closed arm entries in an elevated plus-maze as a measure of anxiety in the rat. J Neurosci Methods. 1985; 14:149-167.

55. Benaroya-Milshtein N, Hollander N, Apter A, Kukulansky T, Raz N, Wilf A, Yaniv I, Pick CG. Environmental enrichment in mice decreases anxiety, attenuates stress responses and enhances natural killer cell activity. Eur J Neurosci. 2004; 20:1341-1347.

56. Sztainberg Y, Kuperman Y, Tsoory M, Lebow M, Chen A. The anxiolytic effect of environmental enrichment is mediated via amygdalar CRF receptor type 1. Mol Psychiatry. 2010; 15:905-917.

57. Ragu Varman D, Rajan KE. Environmental Enrichment Reduces Anxiety by Differentially Activating Serotonergic and Neuropeptide Y (NPY)-Ergic System in Indian Field Mouse (Mus booduga): An Animal Model of Post-Traumatic Stress Disorder. PLoS One. 2015; 10:e0127945.

58. Bahi A. Environmental enrichment reduces chronic psychosocial stress-induced anxiety and ethanol-related behaviors in mice. Prog Neuropsychopharmacol Biol Psychiatry. 2017; 77:65-74.

59. Xu J, Sun J, Xue Z, Li X. An enriched environment reduces the stress level and locomotor activity induced by acute morphine treatment and by saline after chronic morphine treatment in mice. Neuroreport. 2014; 25:701-709.

60. El Rawas R, Thiriet N, Nader J, Lardeux V, Jaber M, Solinas M. Early exposure to environmental enrichment alters the expression of genes of the endocannabinoid system. Brain Res. 2011; 1390:80-89.

61. Floden D, Alexander MP, Kubu CS, Katz D, Stuss DT. Impulsivity and risk-taking behavior in focal frontal lobe lesions. Neuropsychologia. 2008; 46:213-223.

62. Pandey DK, Yadav SK, Mahesh R, Rajkumar R. Depression-like and anxiety-like behavioural aftermaths of impact accelerated traumatic brain injury in rats: a model of comorbid depression and anxiety? Behav Brain Res. 2009; 205: 436-442.

63. Shulz DE, Ego-Stengel V, Ahissar E. Acetylcholine-dependent potentiation of temporal frequency representation in the barrel cortex does not depend on response magnitude during conditioning. J Physiol Paris. 2003; 97:431-439.

64. Moser EI, Krobert KA, Moser MB, Morris RG. Impaired spatial learning after saturation of long-term potentiation. Science. 1998; 281:2038-2042.

65. Wei Z, Meng X, El Fatimy R, Sun B, Mai D, Zhang J, Arora R, Zeng A, Xu P, Qu S, Krichevsky AM, 
Selkoe DJ, Li S. Environmental enrichment prevents $A \beta$ oligomer-induced synaptic dysfunction through mirna-132 and hdac3 signaling pathways. Neurobiol Dis. 2020; 134:104617.

66. Garthe A, Roeder I, Kempermann G. Mice in an enriched environment learn more flexibly because of adult hippocampal neurogenesis. Hippocampus. 2016; 26:261-271.

67.Bevins RA, Besheer J, Palmatier MI, Jensen HC, Pickett KS, Eurek S. Novel-object place conditioning: behavioral and dopaminergic processes in expression of novelty reward. Behav Brain Res. 2002; 129:41-50.

68. Ennaceur A. One-trial object recognition in rats and mice: methodological and theoretical issues. Behav Brain Res. 2010; 215:244-254.

69. Aggleton JP, Albasser MM, Aggleton DJ, Poirier GL, Pearce JM. Lesions of the rat perirhinal cortex spare the acquisition of a complex configural visual discrimination yet impair object recognition. Behav Neurosci. 2010; 124:55-68.

70. Hammond RS, Tull LE, Stackman RW. On the delay-dependent involvement of the hippocampus in object recognition memory. Neurobiol Learn Mem. 2004 Jul;82(1):26-34. doi: 10.1016/j.nlm.2004.03.005. PMID: 15183168 .

71. Rosenzweig MR, Bennett EL. Cerebral changes in rats exposed individually to an enriched environment. J Comp Physiol Psychol. 1972; 80:304-313.

72. Rojas JJ, Deniz BF, Miguel PM, Diaz R, Hermel Edo E, Achaval M, Netto CA, Pereira LO. Effects of daily environmental enrichment on behavior and dendritic spine density in hippocampus following neonatal hypoxia-ischemia in the rat. Exp Neurol. 2013; 241:25-233.

73. Bindu B, Alladi PA, Mansooralikhan BM, Srikumar BN, Raju TR, Kutty BM. Short-term exposure to an enriched environment enhances dendritic branching but not brain-derived neurotrophic factor expression in the hippocampus of rats with ventral subicular lesions. Neuroscience. 2007; 144:412-23.

74. Valencia M, Illanes J, Santander O, Saavedra D, Adaros M, Ibarra A, Saavedra G, Pascual R. Environmental enrichment restores the reduced expression of cerebellar synaptophysin and the motor coordination impairment in rats prenatally treated with betamethasone. Physiol Behav. 2019; 209:112590.

75. Ickes BR, Pham TM, Sanders LA, Albeck DS, Mohammed AH, Granholm AC. Long-term environmental enrichment leads to regional increases in neurotrophin levels in rat brain. Exp Neurol. 2000; 164:45-52.

76. Schrijver NC, Bahr NI, Weiss IC, Würbel H. Dissociable effects of isolation rearing and environmental enrichment on exploration, spatial learning and HPA activity in adult rats. Pharmacol Biochem Behav. 2002; 73:209-224.

77. van Praag H, Kempermann G, Gage FH. Neural consequences of environmental enrichment. Nat Rev Neurosci. 2000; 1:191-198. 


\section{Figure}

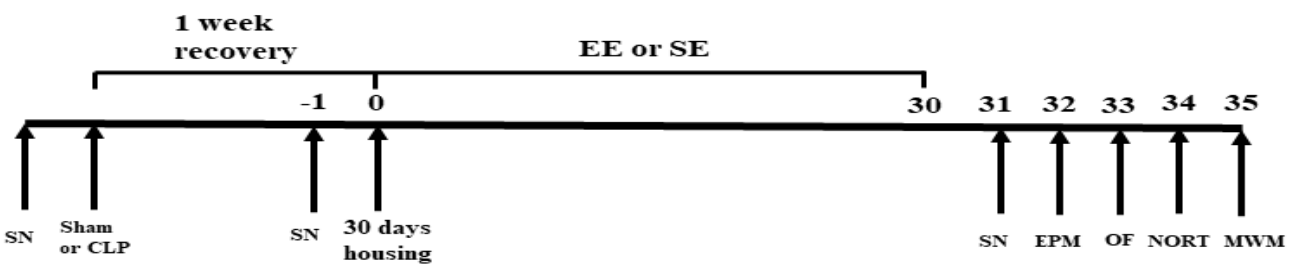

Figure.1 Experimental timeline. The SAE model was made by cecal ligation and perforation 
(CLP) followed by 30 days of housing (either enriched or standard). The following behavioral tests were conducted: sensory neglect $(\mathrm{SN})$, elevated plus maze (EPM), open field test (OF), novel object recognition task (NORT)and Morris water maze (MWM).

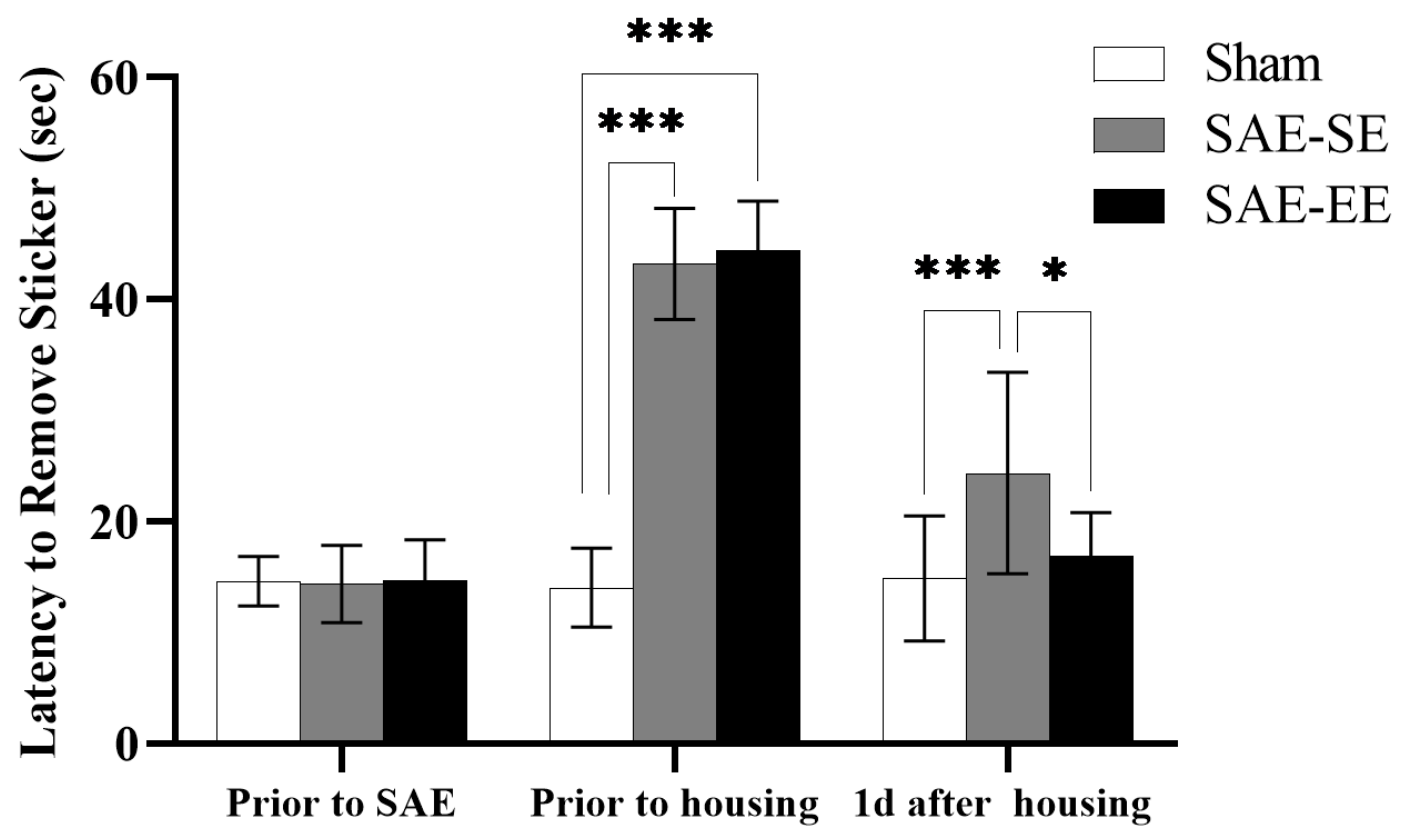

Figure.2 Environmental enrichment attenuated SAE-induced sensory neglect deficits. SAE rats removed the stickers significantly slower than the sham rats prior to housing. And after 30 days housing, rats in the SAE-EE group removed the stickers faster than in the SAE-SE 
group. $* \mathrm{p}<0.05, * * \mathrm{p}<0.01, * * * \mathrm{p}<0.001$. 
A

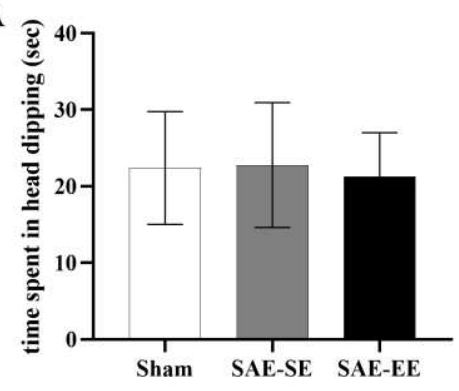

D
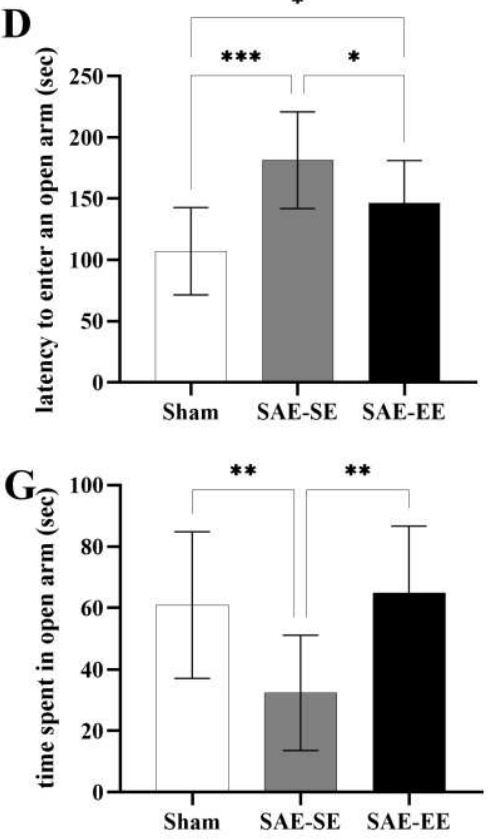

B

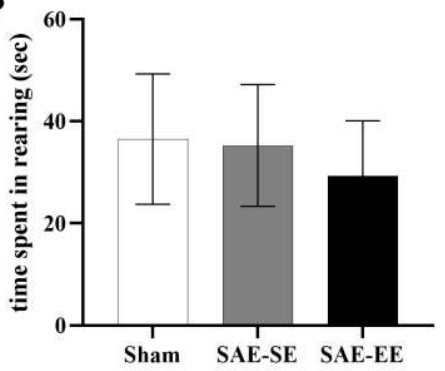

$\mathbf{E}$

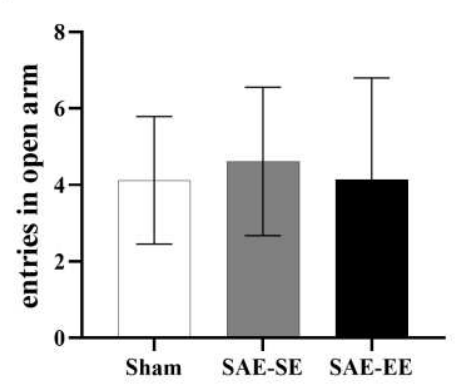

C

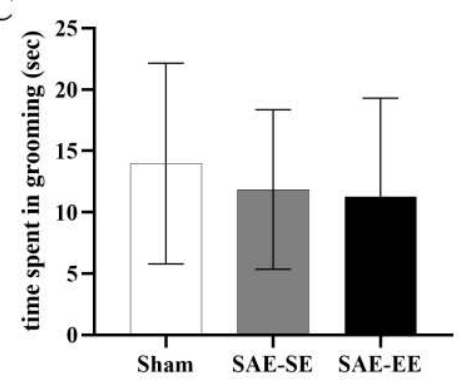

F

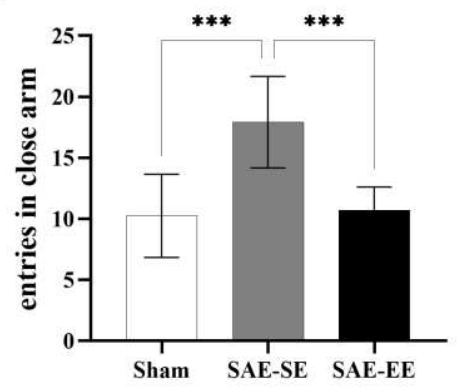

Figure.3 Anxiety-related behaviors after SAE is remedied by environmental enrichment. A,B,C:No significant differences in dipping, rearing or grooming were observed. D: SAE-SE and SAE-EE rats had the longer latency to enter an open arm. At the same time, SAE-EE rats also had decreased escape latency and took shorted time to enter an open arm when compared with SAE-SE rats. E,F: SAE-SE rats exhibited the increased entries in closed arms than SAE-EE or sham rats, while no differences in entries in the open arms were observed. G: SAE-SE rats showed a significantly lower open arm time when compared with sham or SAE-EE rats. $* \mathrm{p}<0.05, * * \mathrm{p}<0.01, * * * \mathrm{p}<0.001$ 
A

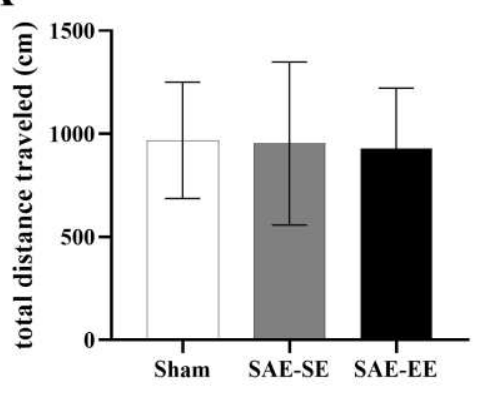

B

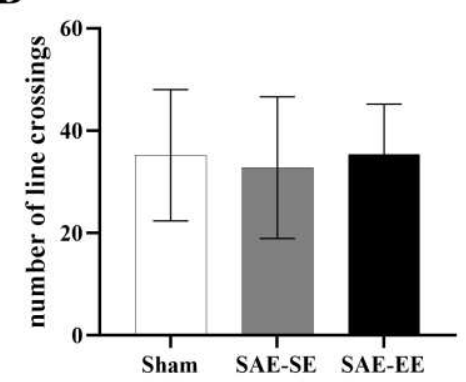

C

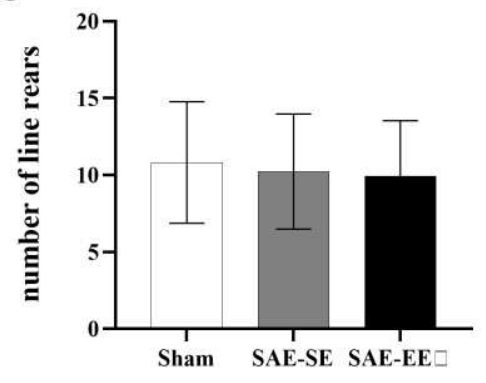

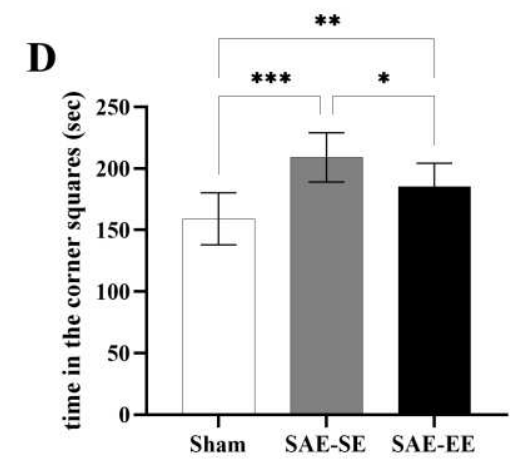

$\mathbf{E}$

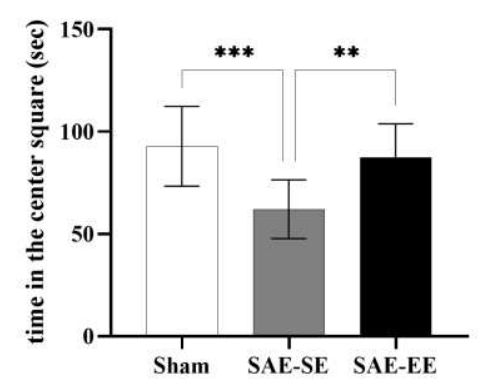

Figure.4 Exploratory activity impairment after SAE is remedied by environmental enrichment. A,B,C:No significant differences were observed in total distance traveled and number of line crossings and rears in the OF test among the three groups. D: SAE-SE rats spent more time in the corner squares compared with sham or SAE-EE rats. E: SAE-SE rats exhibited a significantly lower center square time when compared with sham or SAE-EE rats. $* \mathrm{p}<0.05$, $* * \mathrm{p}<0.01, * * * \mathrm{p}<0.001$ 

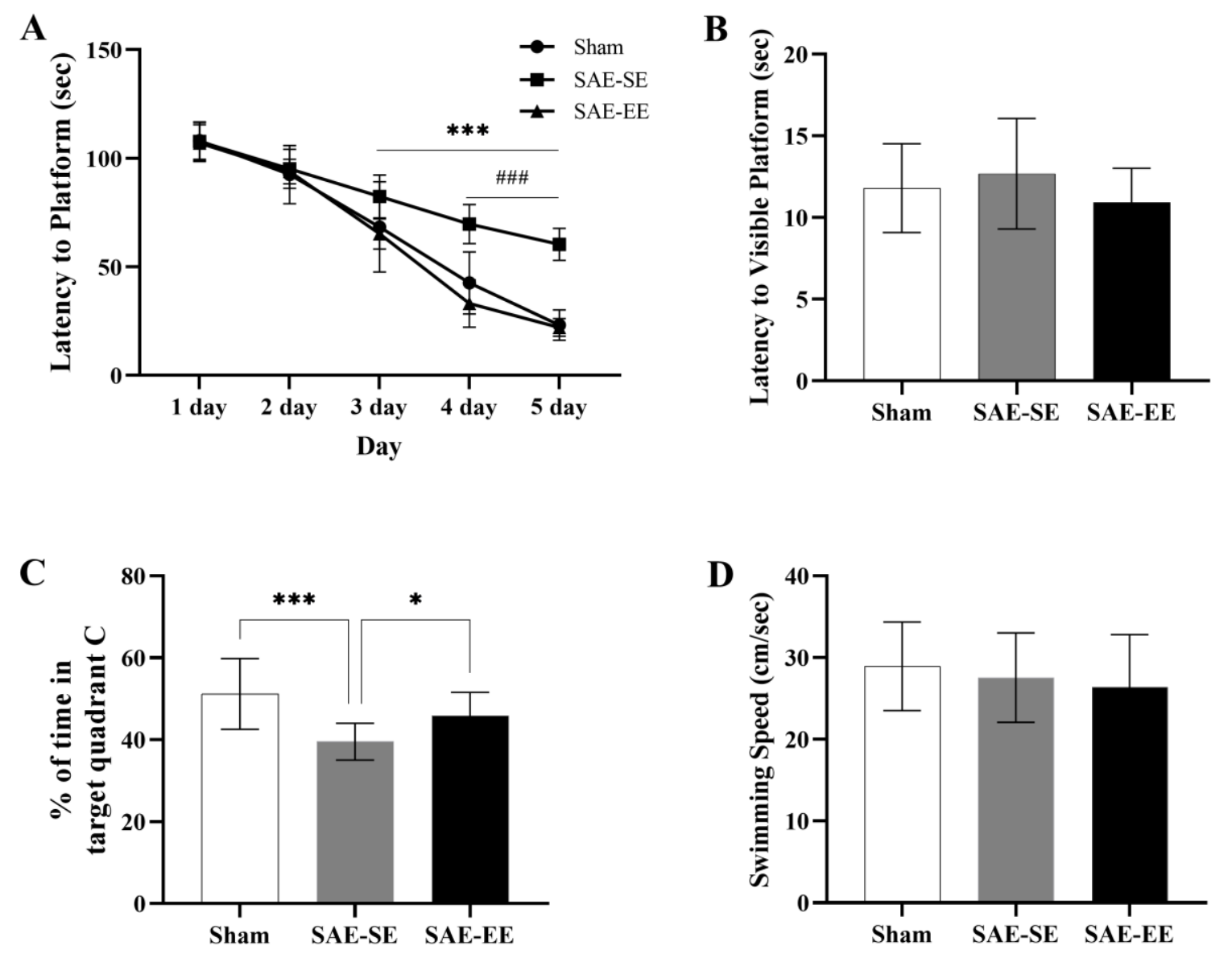

Figure.5 Environmental enrichment ameliorated the SAE-induced spatial learning deficits. A: From 3 day on, the SAE-EE rats performed better latency to platform than the SAE-SE rats. From 4 day on, the sham rats reached the submerged platform quicker than the SAE-SE rats. (SAE-EE VS SAE-SE, ***p $<0.001$; Sham VS SAE-SE, \#\#\#p<0.001). B: No significant differences were observed in latency to visible platform. C:SAE-SE rats spent less time in target quadrant $\mathrm{C}$ compared with sham or SAE-EE rats. D: No significant differences were observed in swimming speed. $* \mathrm{p}<0.05, * * \mathrm{p}<0.01, * * * \mathrm{p}<0.001$. 
A

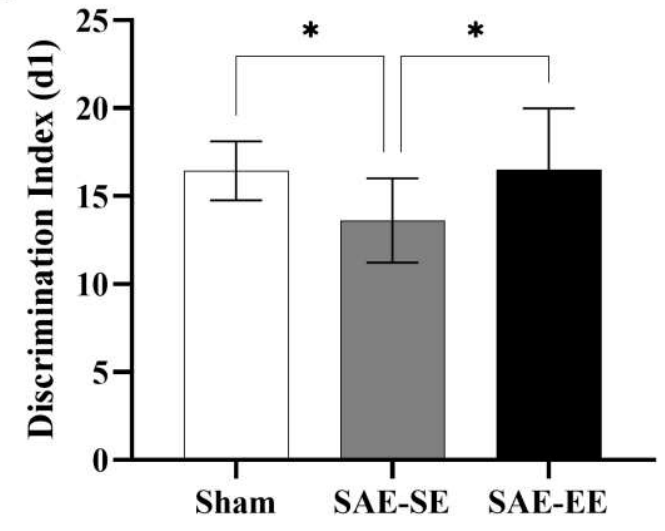

B

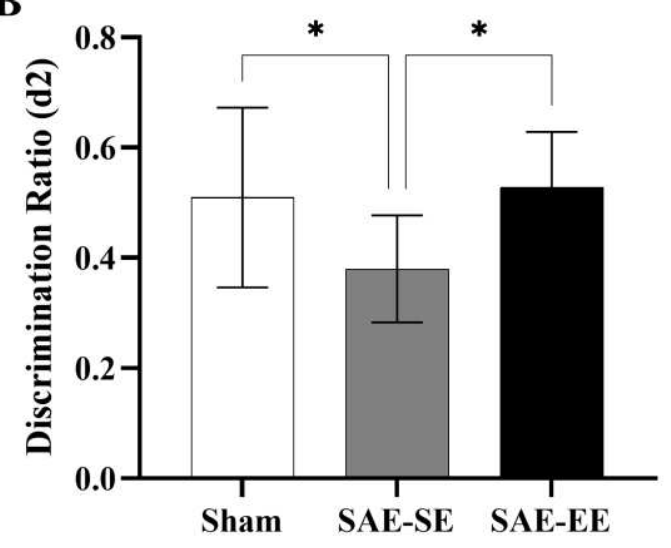

Figure.6 Environmental enrichment effectively to attenuate the SAE-induced recognition memory impairment. A: discrimination index (d1) B: discrimination ratio (d2). SAE-SE rats showed decreased $\mathrm{d} 1$ and $\mathrm{d} 2$ and spent less time exploring novel objects when compared with SAE-EE or Sham rats. $* \mathrm{p}<0.05, * * \mathrm{p}<0.01, * * * \mathrm{p}<0.001$. 


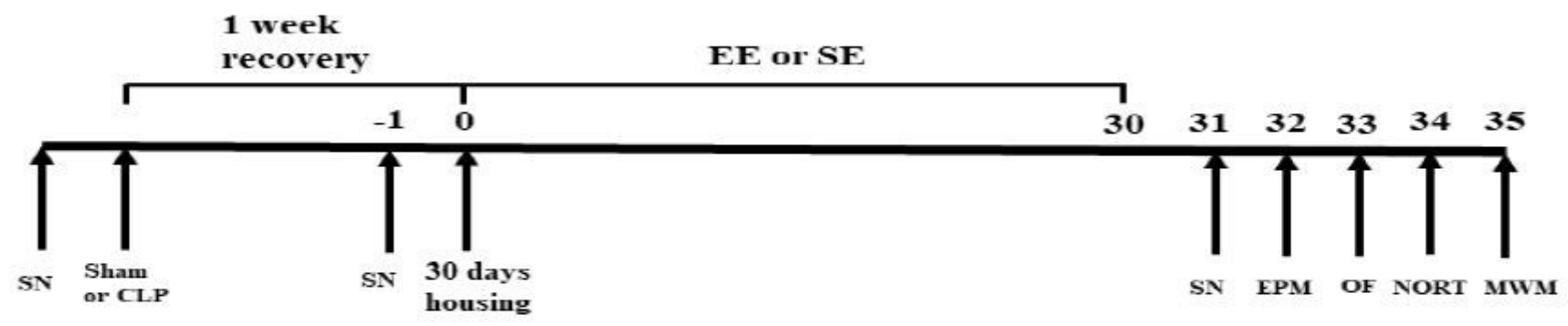

\section{Figure 1}

Experimental timeline. The SAE model was made by cecal ligation and perforation (CLP) followed by 30 days of housing (either enriched or standard). The following behavioral tests were conducted: sensory neglect (SN), elevated plus maze (EPM), open field test (OF), novel object recognition task (NORT)and Morris water maze (MWM). 


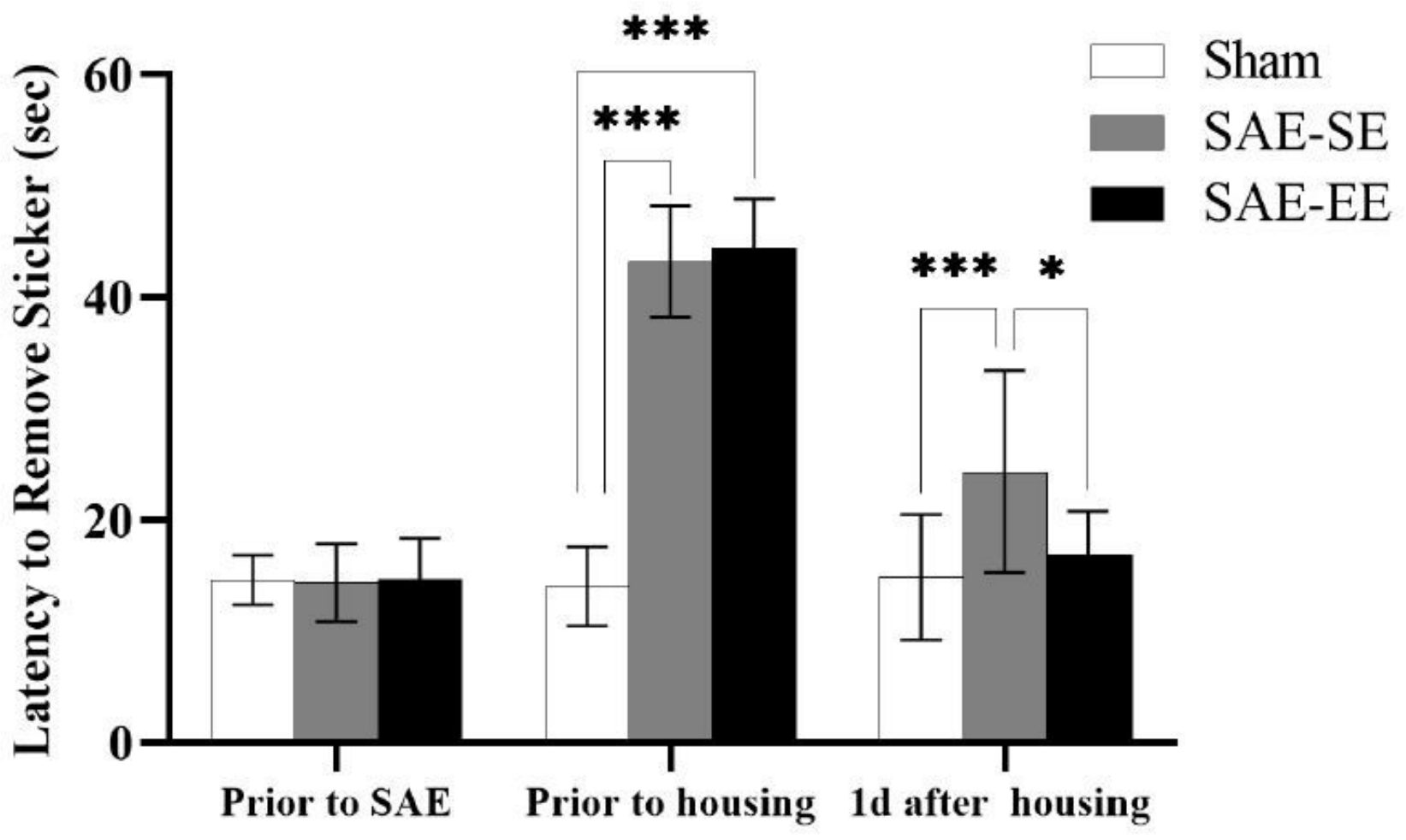

Figure 2

Environmental enrichment attenuated SAE-induced sensory neglect deficits. SAE rats removed the stickers significantly slower than the sham rats prior to housing. And after 30 days housing, rats in the

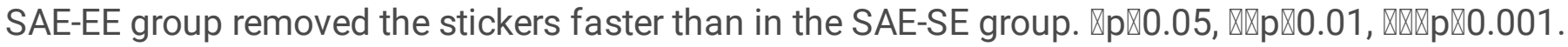


A

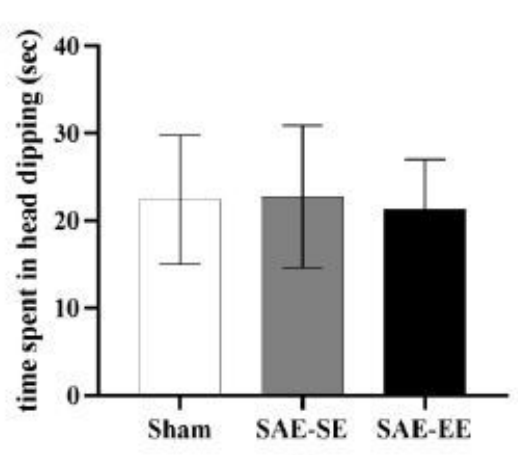

D
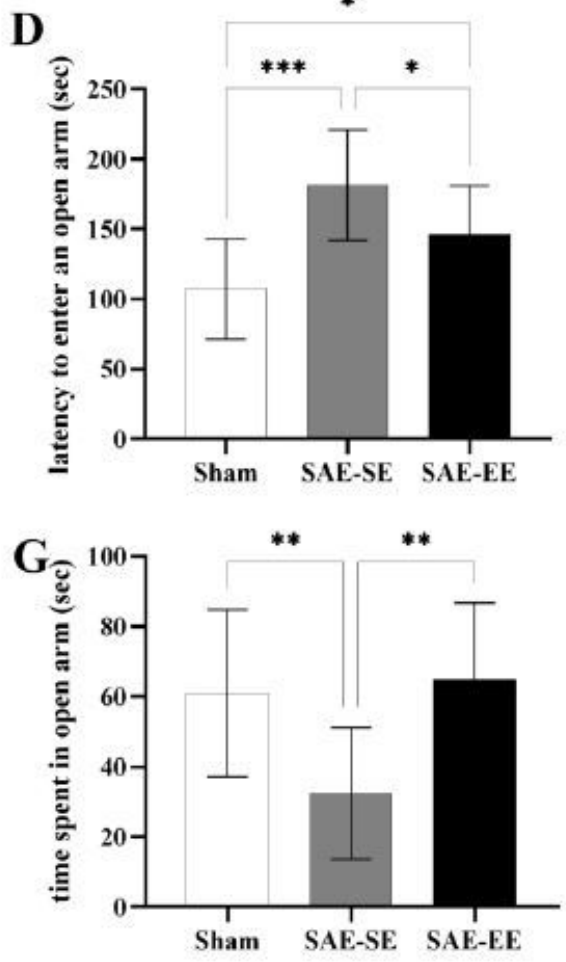

B

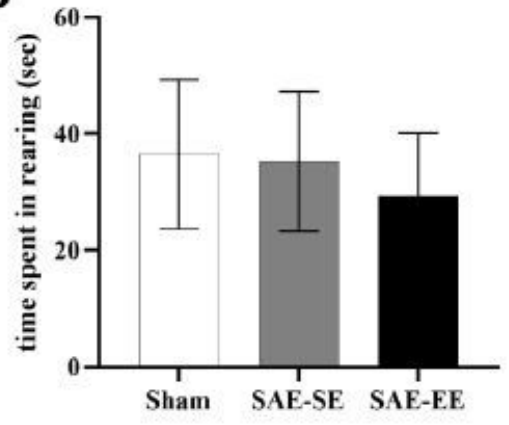

$\mathbf{E}$

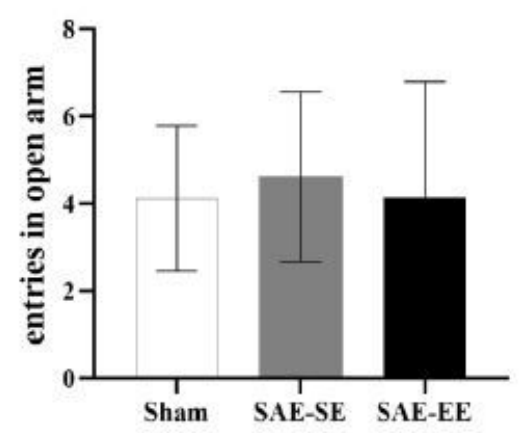

C

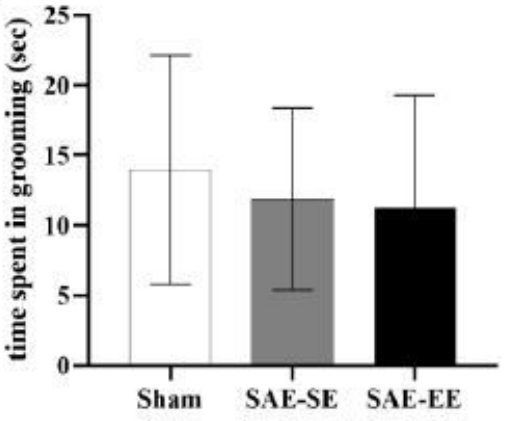

F

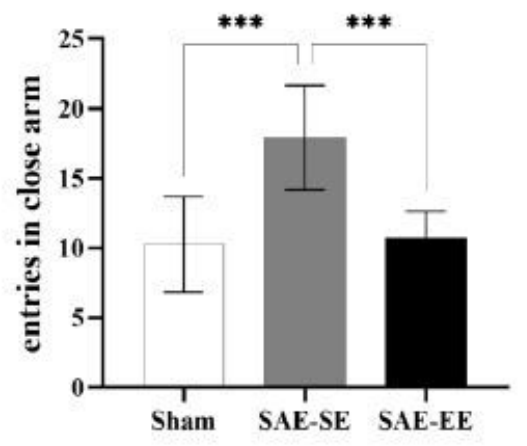

\section{Figure 3}

Anxiety-related behaviors after SAE is remedied by environmental enrichment. A,B,C:No significant differences in dipping, rearing or grooming were observed. D: SAE-SE and SAE-EE rats had the longer latency to enter an open arm. At the same time, SAE-EE rats also had decreased escape latency and took shorted time to enter an open arm when compared with SAE-SE rats. E,F: SAE-SE rats exhibited the increased entries in closed arms than SAE-EE or sham rats, while no differences in entries in the open arms were observed. G: SAE-SE rats showed a significantly lower open arm time when compared with

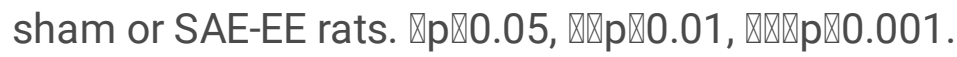


$\mathbf{A}$

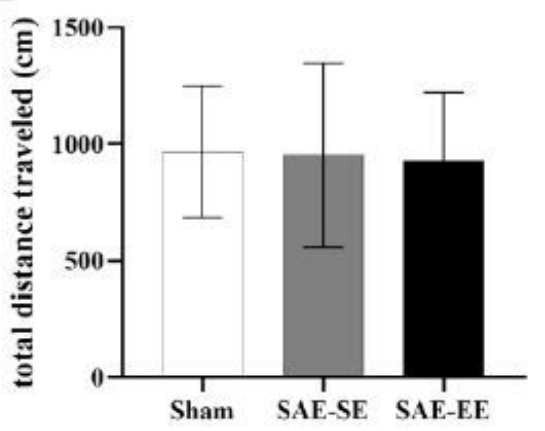

B

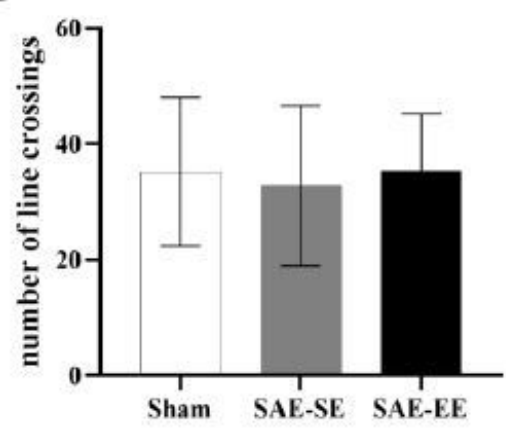

C

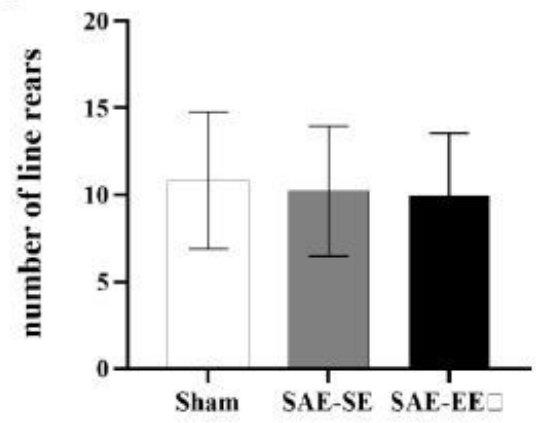

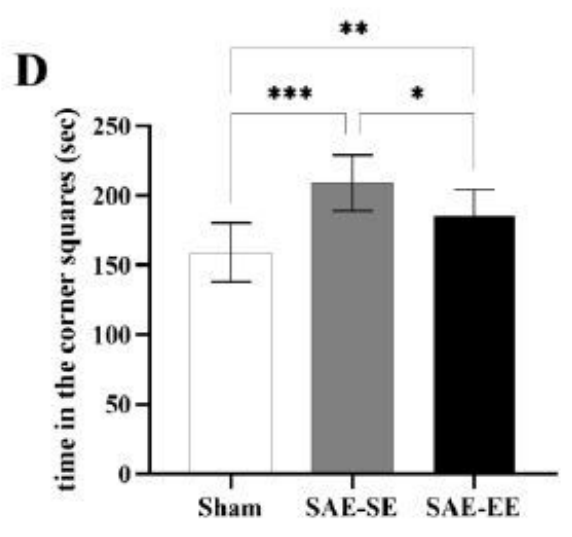

$\mathbf{E}$

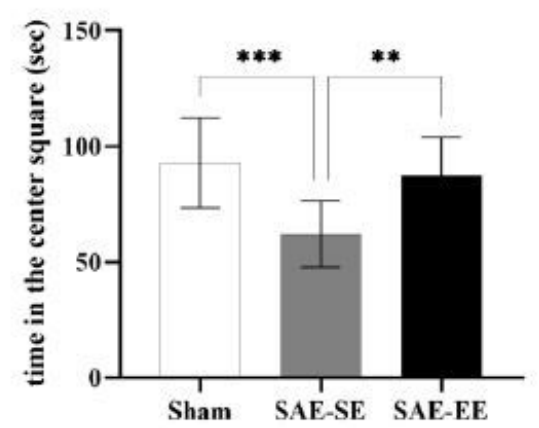

\section{Figure 4}

Exploratory activity impairment after SAE is remedied by environmental enrichment. A,B,C:No significant differences were observed in total distance traveled and number of line crossings and rears in the OF test among the three groups. D: SAE-SE rats spent more time in the corner squares compared with sham or SAE-EE rats. E: SAE-SE rats exhibited a significantly lower center square time when compared with sham

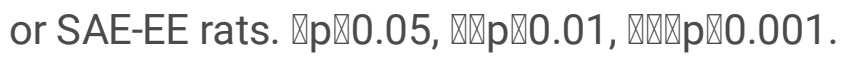


A

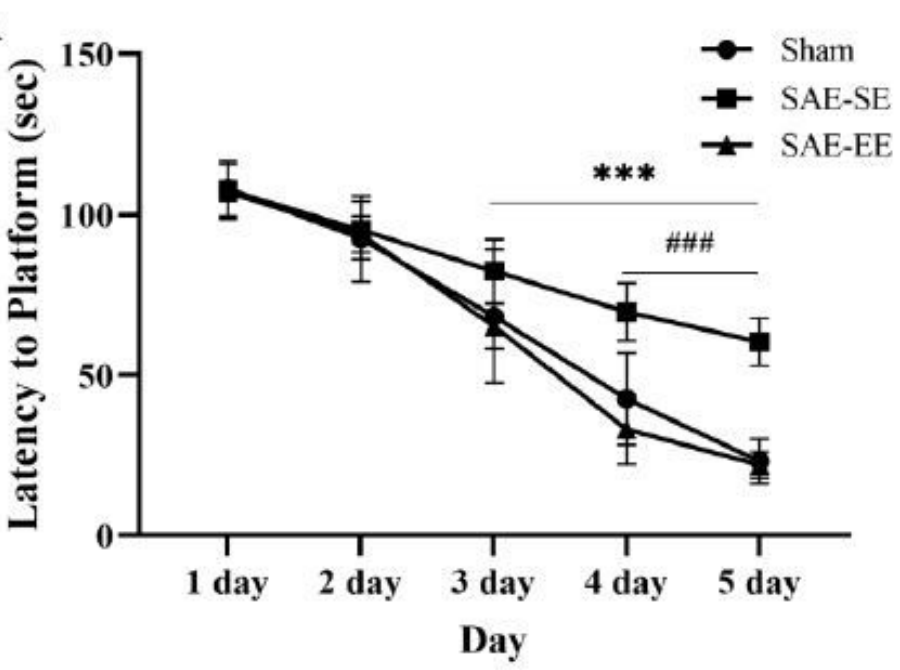

C

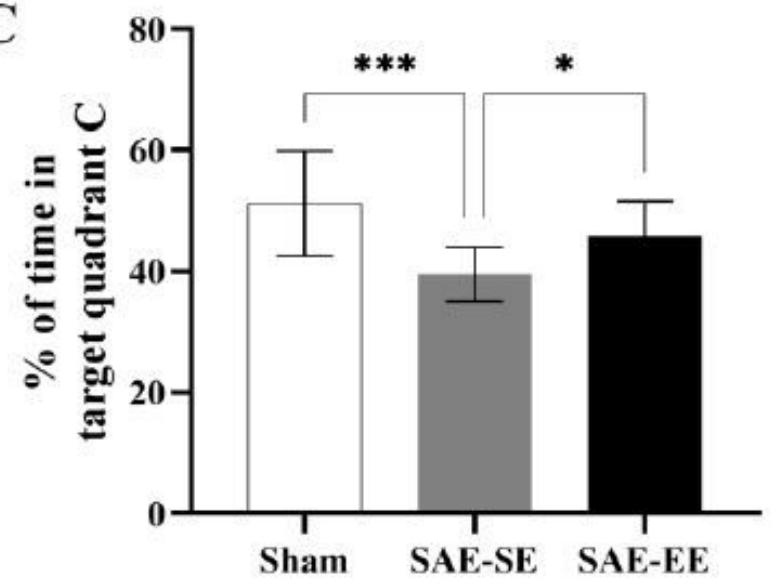

B

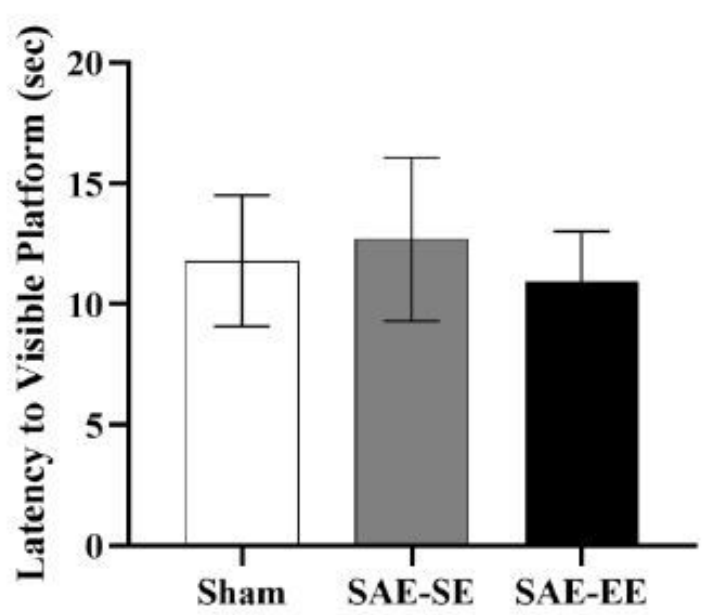

D

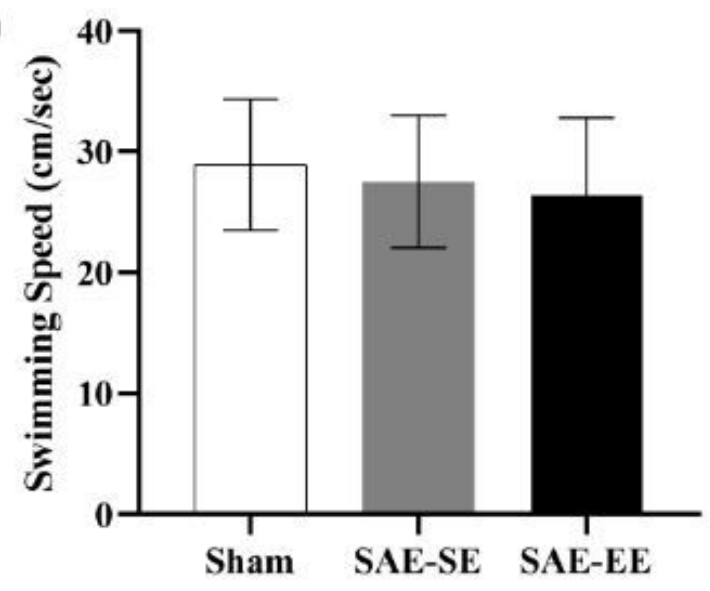

Figure 5

Environmental enrichment ameliorated the SAE-induced spatial learning deficits. A: From 3 day on, the SAE-EE rats performed better latency to platform than the SAE-SE rats. From 4 day on, the sham rats

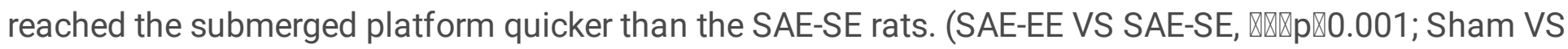
SAE-SE, \#\#\#p囚0.001). B: No significant differences were observed in latency to visible platform. C:SAE$\mathrm{SE}$ rats spent less time in target quadrant $\mathrm{C}$ compared with sham or SAE-EE rats. D: No significant

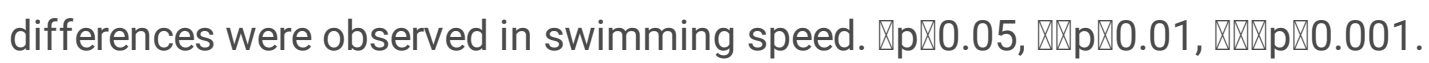


A

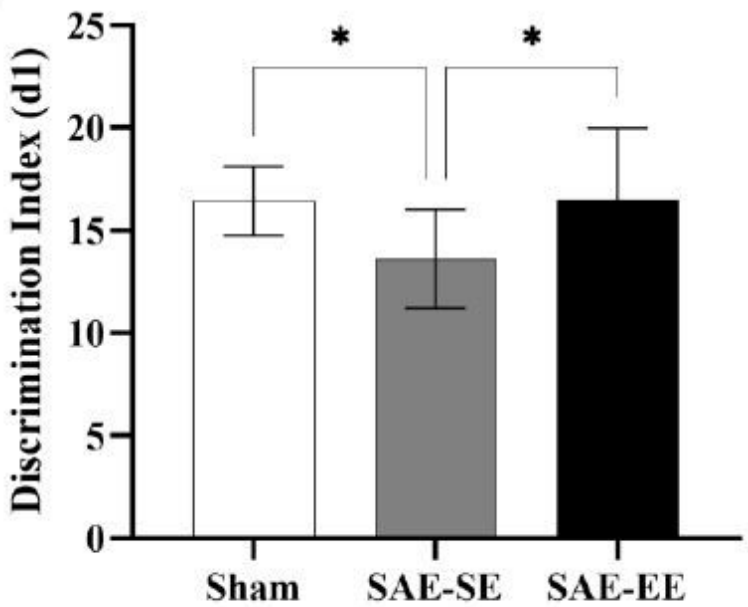

B

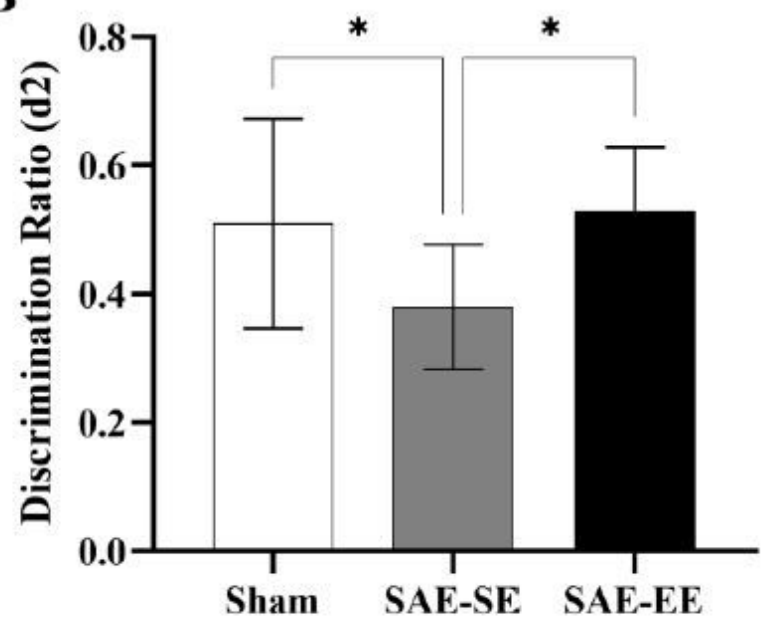

Figure 6

Environmental enrichment effectively to attenuate the SAE-induced recognition memory impairment. A: discrimination index (d1) B: discrimination ratio (d2). SAE-SE rats showed decreased d1 and d2 and

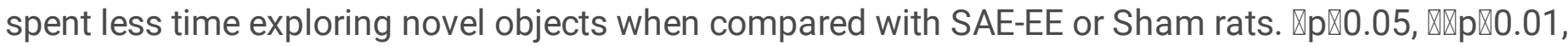
$\triangle \mathbb{Q} \otimes \mathrm{p} \otimes 0.001$. 